\title{
Doxa legítima y el desarrollo social*
}

\author{
Doxa in a legitimate sense and social development
}

Doxa legitima e o desenvolvimento social

Recibido el 20 de octubre de 2015. Aceptado el 19 de noviembre de 2016

\author{
John Fredy Zuluaga Duque**2 \\ Colombia
}

- Para citar este artículo:

Zuluaga Duque, John Fredy (diciembre, 2016). Doxa legítima y el desarrollo social. Ánfora, 23(41), 107-131. Universidad Autónoma de Manizales. ISSN

0121-6538.

\section{Resumen}

Objetivo: identificar los criterios del sentido común de Tomás Reid para presentar una resignificación y caracterizar la disputa crítica como un mecanismo metodológico que permite transformar las opiniones del sentido común y el conocimiento de la doxa legítima. Además, se busca establecer cómo la democratización del conocimiento posibilita la apropiación de la doxa legítima. Metodología: se usó el método hermenéutico como herramienta conceptual de selección, análisis e interpretación de categorías y datos. Resultados: se encontró que el sentido común no se entiende como una colección de principios autoevidentes, sino como una serie de conjeturas básicas que sirven para fundar conjeturas complejas, a partir de las cuales los individuos y las colectividades piensan y transforman el mundo. No todas las creencias del sentido común son verosímiles; es necesario filtrar las creencias falsas mediante un

\footnotetext{
* Este artículo corresponde a la investigación "Tras la democratización de los saberes: La relación entre gestión del conocimiento, inteligencia colectiva y desarrollo social”, que se realizó para optar al título de Doctor en filosofía de la Universidad de Antioquia. La investigación se inició en enero de 2011 y se concluyó en febrero de 2015". Fue financiado por el Centro de Desarrollo I.A.I (Ideas y Acciones Inteligentes).

** Magister en filosofía. Profesor de la Universidad de Antioquia. Correo electrónico: paideiasophos@ hotmail.com
} 
mecanismo metodológico denominado disputa crítica, el cual intersecciona dos tipos de metodologías las justificacionistas y las falibilistas. Conclusiones: se concluye que luego de que la doxa se haya legitimado se transfiere a la sociedad haciendo uso de un sistema de transferencia que implica democratizar, divulgar, apropiar y popularizar el conocimiento.

Palabras claves: Sentido común, Doxa, Disputa, Democracia

\begin{abstract}
Objective: to identify the criteria of the common sense of Thomas Reid to present a new resignification and characterize the critical dispute as a methodological mechanism to transform the views of the common sense and the knowledge of the legitimate doxa. In addition, it seeks to stablish how the democratization of knowledge enables the appropriation of the legitimate doxa. Methodology: the hermeneutical method was used as a conceptual selection tool, analysis and interpretation of categories and data. Results: it was found that common sense is not understood as a collection of self - evident principles, but as a series of basic assumptions used to establish complex conjectures, from which individuals and communities think and transform the world. Not all the common-sense beliefs are credible; it is necessary to filter out the false beliefs through a methodological mechanism called critical dispute, which intersects two types of methodologies: the justificationists and fallibilists. Conclusions: it is concluded that after the doxa has been legitimated, it is transferred to the society using a transfer system that involves to democratize, disclose, appropriate and popularize knowledge.
\end{abstract}

Keywords: Common Sense, Doxa, Dispute, Democracy

\title{
Resumo
}

Objetivo: identificar os critérios do sentido comum de Tomás Reid para apresentar uma ressignificação e caracterizar a disputa crítica como um mecanismo metodológico que permite transformar as opiniões do sentido comum e o conhecimento da doxa legítima. Além disso, busca-se estabelecer como a democratização do conhecimento possibilitaaapropriaçãodadoxalegítima. Metodologia:usou-seométodohermenêutico como ferramenta conceitual de seleção, análise e interpretação de categorias e dados. Resultados: encontrou-se que o sentido comum não se entende como uma coleção de princípios auto evidentes, senão como uma série de conjecturas básicas que servem para 
fundar conjecturas complexas, a partir das quais os indivíduos e as coletividades pensam e transformam o mundo. Não todas as crenças do sentido comum, são verosímeis; é necessário filtrar as crenças falsas mediante um mecanismo metodológico denominado disputa crítica, o qual intersecciona dois tipos de metodologias as justificacionistas e as falibilistas. Conclusões: conclui-se que logo que a doxa tenha se legitimado se transfere à sociedade fazendo uso de um sistema de transferência que implica democratizar, divulgar, apropriar e popularizar o conhecimento.

Palavras chave: Sentido comum, Doxa, Disputa, Democracia 


\section{Introducción}

Muchos de los saberes tradicionales y del sentido común dejan de ser valorados y apropiados, n la actualidad. Esto, porque se aprecian más los conocimientos avalados por paradigmas científicos y se tiende a desdeñar los saberes que no satisfagan los estándares de las ciencias. Esta realidad reduce el patrimonio cognitivo de la humanidad en su conjunto y afecta el desarrollo endógeno de muchas colectividades. De allí la necesidad de enriquecer el debate en torno a la re-significación del sentido común y de la legitimación de los saberes no estrictamente científicos. Así, es propio preguntar ¿Cómo es posible legitimar y democratizar los saberes distintos a los científicos, incluyendo los saberes del sentido común, en aras de mejorar el patrimonio cognitivo de los colectivos?

Los objetivos a alcanzar son los siguientes: 1) Re-significar la definición de sentido común propuesta por Tomas Reid y describir sus características; 2) Señalar un mecanismo metodológico que posibilite depurar las opiniones (doxa ${ }^{1}$ ), las ideas, los dogmas y las creencias del sentido común que puedan ser falsas, de forma tal que el sentido común se pueda robustecer y cumplir su función de ser la base de los colectivos inteligentes y 3) Mostrar los procesos que permiten democratizar los saberes y construir sociedades con desarrollo progresivo.

Es frecuente escuchar que el sentido común es el menos común entre los individuos. Esta afirmación matiza una verdad más profunda: los individuos se han acostumbrado a no pensar por sí mismos. Les basta con que el contador administre las cuentas, el médico alivie la enfermedad y el técnico arregle máquinas. "No me hace falta pensar, siempre que pueda pagar; otros asumirán por mí tan engorrosa tarea" (Kant, 2012, p. 7).

Una vez que el individuo, por la angustia del pensar, deja en manos de terceros su propio pensamiento, la autonomía intelectual de cada persona se reduce y la libertad de tomar decisiones también se mengua. En términos colectivos, la interacción de individuos es la que crea las dinámicas y los hechos sociales; si una sociedad tiene individuos con un sentido común poco desarrollado, la forma que la sociedad resolverá sus problemas en conjunto será poco prometedora. "Comprender el papel de agencia es, pues, fundamental para reconocer que las personas son personas responsables: no sólo estamos sanos o enfermos sino que, además, actuamos o nos negamos a actuar de una u otra forma” (Sen, 2000, p. 234).

1 "La distinción de Platón (episteme frente a doxa) deriva de Jenófanes (verdad frente a conjetura o apariencia) a través de Parménides" (Popper, 1967, p. 108). 
En las actuales economías ${ }^{2}$ y sociedades del conocimiento ${ }^{3}$, los individuos y los colectivos que no gestionen los saberes de forma pertinente tendrán, a la postre, una regresión en su desarrollo. Por ende, estudiar las relaciones existentes entre sentido común, doxa legítima, inteligencia colectiva y desarrollo social es indispensable en una realidad en la que el mayor capital es el conocimiento y donde el mayor activo que tiene cada individuo es su capacidad de razonar y resolver problemas. "El costo del recurso básico, que es el cerebro, está subiendo rápidamente y ya es muy alto” (Drucker, 2013, p. 64).

Si bien este articulo únicamente pretende señalar una ruta metodológica que puede ser usada para legitimar distintos saberes, también es cierto, que puede servir como insumo para suscitar nuevos debates en torno a la forma como se produce, gestiona y apropia el conocimiento; lo cual resulta substancial a la hora de pensar en la supervivencia de las personas y en su respectiva calidad de vida.

\section{Metodología}

En esta investigación cualitativa el principal procedimiento utilizado fue la fundamentación teórica de las categorías: sentido común, doxa legítima y desarrollo social. Primero, se analizó la teoría del sentido común propuesta por Tomás Reid en el texto Investigaciones sobre la mente humana. El segundo proceso fue fundamentar el mecanismo de la disputa crítica, como metodología para legitmar la doxa. Se analizó el falibilismo partiendo del racionalismo crítico desarrollado por Popper y se analizó el justificacionismo partiendo del pensamiento escolástico propuesto por Santo Tomás de Aquino, en su texto El tratado de la ley y el tratado de la justicia. Finalmente, se estudió la teoria de desarrollo social propuesta por Amartya Sen en su texto Desarrollo y libertad. Tambien se analizaron categorías modernas de desarrollo social implícitas en la obra de David Hume, en sus ensayos políticos. El método de análisis, interpretación de datos, procesamiento de información, obtención de resultados y sustentación teórica, usado en esta investigación fue el método hermenéutico.

\footnotetext{
2 La tendencia hoy en las economías es que se base en el conocimiento. "Las industrias que han ocupado el centro de la economía en los últimos 40 años, tienen como negocio la producción y distribución de saber e información en lugar de la producción y distribución de cosas" (Durcker, 1993, p. 181).

3 "La sociedad futura será una sociedad del conocimiento. Su recurso clave será el conocimiento y los trabajadores del conocimiento serán el grupo dominante de su población activa” (Ducker, 2013, p. 197).
} 


\section{Resultados}

Los hallazgos de la investigación se exponen en tres momentos: en el primero, se caracterizará y resignificará el sentido común desde la filosofía de Tomas Reid. En el segundo momento se mostrará de qué manera opera el mecanismo metodológico denominado disputa crítica, el cual posibilita depurar las creencias del sentido común y legitimar la doxa. Y en el tercer momento se mostrará cómo funcionan los mecanismos de democratización y apropiación de los conocimientos y de la doxa legítima.

\section{1) Caracterización y resignificación del sentido común desde la perspectiva de Tomas Reid}

Para Thomas Reid, considerado el padre de la teoría fundamentadora del sentido común (SC), define el término como una colección de principios autoevidentes, cuyo origen no se funda, ni en la razón, ni en la sensación, ni en la experiencia, sino que emerge de la misma naturaleza humana; estos principios indemostrables en sí mismos son la fuente de todo conocimiento.

Una de las características fundamentales que el filósofo escocés atribuye al $\mathrm{SC}$, es que funciona como instrumento para demostrar otras proposiciones. Verbigracia: se puede justificar la siguiente proposición: la obra El quijote de la Mancha fue significativa para un intérprete como Sigmund Freud, partiendo de dos supuestos indemostrables del sentido común: a) existe un mundo externo independiente de un sujeto que lo piensa, y b) existen otros seres inteligentes que han creado obras de arte literario. Basados en estos dos principios autoevidentes, se podría pasar a mostrar: c) El quijote de la Mancha es una obra literaria, d) esta obra fue elaborada por Miguel de Cervantes Saavedra, e) esta obra fue leída por Sigmund Freud, y f) la obra generó un impacto psicológico en Freud, tal como él mismo lo confiesa. Según Reid, los postulados a) y b) hacen parte del SC y son fuentes para el conocimiento; sin éstos no sería posible demostrar la cadena de razonamientos $\mathrm{c}, \mathrm{d}$, e, f.

Para Reid, el reconocimiento de la identidad (I), la aceptación de que los objetos poseen propiedades extrínsecas e intrínsecas (II), la conformidad de que existen otras mentes (III), el acuerdo según el cual existe una relación entre seres y objetos (V), la aceptación de los axiomas lógicos (VI), el aval de verdades éticas (VII), entre otras creencias, son condición necesaria, mas no suficiente, 
para probar otras verdades. Este conjunto de creencias (I, II, III, IV ...) son principios del SC $\mathrm{S}^{4}$.

Thomas Reid fundamenta su definición del SC en principios fijos de la naturaleza humana. Por el contrario, en general las personas que buscan defender una definición alejada de esta versión inicial, piensan que la base del SC no son principios autoevidentes, sino conjeturas básicas que sirven para fundar conjeturas más complejas, a partir de las cuales un sujeto o una colectividad pueden explicar o actuar en el mundo. Para Reid, los principios del SC son estáticos; sin embargo, no es osado afirmar que las conjeturas que conforman este sentido son dinámicas, pues se transforman en la medida en que cambia la realidad.

Es preferible, entonces, revisar la definición de SC y resignificarlo. El sentido común no es sólo una facultad innata de la naturaleza humana como piensa Reid; el SC se modifica a la par con el cambio de la realidad. Por ende, es menester proponer una definición nueva e intuitiva de esta facultad humana. ¿ंA qué se refiere, pues, cuando se habla de SC renovado? El SC es un conjunto de creencias (siempre falibles) tanto falsas como verdaderas, ampliamente aceptadas por una sociedad, las cuales son aplicadas por los sujetos para resolver problemas y adaptarse a la realidad. "El sentido común opone regularmente los hechos a las teorías, las verdades a las opiniones, lo que es objetivo a lo que no lo es, señalando por consiguiente qué opiniones se han de preferir antes que otras, ya se fundamente o no esta preferencia en criterios aceptados por lo general" (Perelman y Olbrechts-Tyteca, 1989, p. 769).

Ahora bien, es indispensable en adelante analizar el rol que juega el sentido común en la creación de dinámicas inteligentes que impacten positivamente la sociedad.

Tal como lo reconoció Hume (1990) para pertenecer a un grupo social es necesario, como mínimo, que sus miembros posean creencias, costumbres y propósitos similares (pp. 111-113). Es este fuerte sentimiento de sociabilidad el que contribuye a formar el SC. El neófito miembro de un grupo social, por la fuerza de la costumbre impuesta por un grupo y por el afán de no ser excluido, aprende rápidamente a pensar y actuar como el colectivo.

4 Para un análisis más detallado se recomienda leer la introducción que hace Ellen Duthie del texto de Thomas Reid "Investigación sobre la mente humana, según los principios del sentido común" (Reid, 2004). 
En esta línea discursiva, el SC cumple la función de otorgar a los individuos un conjunto de creencias, hábitos y objetivos, que constituyen la base para adaptarse a la sociedad. Este es el proceso que permite conservar el SC en la sociedad, pues hace que los individuos se apeguen a la costumbres y se anclen a las tradiciones. Por otro lado, el SC funciona como la materia prima necesaria para iniciar los procesos críticos de construcción de conocimiento, pues al estar compuesto de creencias verdaderas y de falsas, ocurre que éstas últimas, una vez son aplicadas a la solución de problemas y no resultan ser funcionales, los individuos las critican y derrumban, dando paso a la creación de nuevas conjeturas que enriquezcan la base del SC.

Este conflicto promueve las dinámicas sociales y estimula el desarrollo social. Las ratificaciones o refutaciones de las creencias del SC se realizan por medio de las Disputas Críticas (DC); de esta manera, el SC aporta la materia prima para someter a examen crítico el conjunto de creencias, costumbres y tradiciones de una sociedad. Estas DC únicamente pueden crecer en sociedades abiertas -en sentido popperiano- que estimulen la libertad de pensamiento y acción, donde los individuos puedan, sin coerción, desplegar su razón discursiva y su praxis transformadora.

En seguida se explica en qué consiste el mecanismo conceptual denominado aquí disputa crítica (DC). La disputa crítica funciona como un filtro conceptual que pone a prueba los saberes, ya sea mediante la justificación de las creencias que se suponen verdaderas ${ }^{5}$ o la refutación de las creencias que se suponen falsas. Al final del proceso de DC el sentido común se depura de las creencias falsas y en consecuencia se robustece.

\section{2) Disputa crítica: Mecanismo metodológico que posibilita la legitimación de la doxa}

Primero se justificará la necesidad de introducir un mecanismo con la flexibilidad lógica y metodológica capaz de optimizar nuestra capacidad de separar las creencias falsas de las verdaderas que están insertas en el sentido común. Luego, se mostrarán las propiedades de la DC, esto es, se expondrá la forma en la cual el mecanismo funciona con su doble naturaleza justificacionista y falibilista.

\footnotetext{
5 "Las dificultades que se lazan en el camino de la comprensión del mundo real son casi sobrehumanas, y sólo muy pocos -si es que hay alguno- pueden llegar al estado divino de la comprensión del mundo real, al estado divino del verdadero conocimiento, de la episteme" (Popper, 1967, p. 32
} 
Sería un contrasentido encontrar un argumento suficiente y necesario para demostrar, de forma definitiva, que, por lo menos, la afirmación "todo conocimiento es conjetural”, posee la característica de certeza. Empero, no hay una prueba de ese calibre. Cuando se desea persuadir a alguien para que crea en esa afirmación, se echa mano de juicios metafísicos de la forma: a) la realidad es dinámica y, dado este cambio continuo, lo que se conoció ayer, cambiará mañana ${ }^{6}$. Sin embargo, se podría aceptar un argumento que no fuera de naturaleza ontológica, ni epistemológica, como el anterior que resalta un mundo cambiante y una mente limitada, sino de uno que fuera de carácter emocional, teleológico o de otro tipo.

Al respecto se puede mencionar los siguientes: b) El hombre desea conocer el mundo y aunque tal entendimiento se escurre, es posible gozar: 1) construyendo teorías más exitosas y renovarlas cuando éstas pierdan su funcionalidad para atrapar la abundancia de lo dado; disfrutar 2) siendo libres para innovar, cambiar y transformar lo dado a la experiencia; 3) escapar de los totalitarismos en que desembocan las posturas dogmáticas; y 4) huir de la desesperanza en que se hunden los escépticos pesimistas ${ }^{7}$.

La exuberancia del universo, la naturaleza y la cultura siempre han cautivado al hombre, siempre hemos deseado develar sus más íntimos secretos. Los escépticos han dicho que la riqueza de lo dado escapa a la comprensión. "En la época moderna y, especialmente en años recientes, el escepticismo en la filosofía ha llegado a ser considerado como el punto de vista de que nada sabemos, o de que nada es cierto o de que todo puede ponerse en duda” (Stroud, 1991, p. 9).

Pero ¿estamos dispuestos a renunciar a la conquista de la abundancia ${ }^{8}$ del mundo? Los dogmáticos han intentado, por años, enseñar que la realidad es un libro que se revela con certezas ante nosotros. Esta posición se sustenta en una confianza en la razón humana, todavía no debilitada por ninguna duda (Hessen, 1994, p. 25). Sin embargo, ¿es tan pobre la realidad como para no continuar

\footnotetext{
6 Argumentos de este tipo fueron desarrollados desde el empirismo moderno. Ver: (Hume, 1990, p. 131).

7 Cuando Hume (1990, p. 225) señala que: "Siendo nuestra mente estrechay pobre, no podremos extender nuestros conceptos a la diversidad y extensión de la naturaleza, a menos queimaginemosque ésta es tan limitada en sus operaciones como lo somos nosotros en nuestra especulación"; ciertamente reconoce que el mundo excede nuestra comprensión, más no renuncia a conocer, su duda no lo absorbe. De hecho, el filósofo escocés aconseja escapar del escepticismo pesimista pirrónico y nos recuerda que es la misma naturaleza la que nos obliga a escapar de la duda. "La filosofía nos volvería completamente pirrónicos si la naturaleza no fuera demasiado fuerte para ello" (Hume, 1990, p. 143).

8 Término introducido por Feyerabend en su texto "Conquista de la abundancia" (Feyerabend, 2001).
} 
transformándose?; ¿Las mentes humanas están lo suficientemente desarrolladas como para percibir tanto las milimétricas como las macrométricas transformaciones del mundo?

De otro modo, los defensores de la doxa legítima intentan mostrar que es posible, por medio del ejercicio de la disputa crítica, poner a prueba positiva (justificar) o negativa (refutar) las teorías que se tienen acerca del mundo; que es posible, guiados por un ideal regulador (la verdad), continuar atrapando la abundancia en las redes conceptuales. "Combatimos las opiniones filosóficas, tajantes e irreductibles, que nos presentan los absolutismos de cualquier índole: el dualismo de la razón y la imaginación, de la ciencia y la opinión, de la evidencia irrefragable y la voluntad engañosa, de la objetividad universalmente admitida y la subjetividad incomunicable, de la realidad que se impone a todos y los valores puramente individuales" (Perelman y Olbrechts, 1989, p. 767).

Resulta útil introducir la Disputa Crítica (DC) para resaltar la necesidad de conservar y estimular la naturaleza dual que debe caracterizar la búsqueda racional del conocimiento, donde se muestran, por un lado, los compromisos justificacionistas por probar las teorías y, por el otro, los esfuerzos falibilistas por refutar las teorías. Esta doble naturaleza nutre los debates e impulsa el crecimiento del conocimiento. En este sentido, la DC se erige como un mecanismo complementario que une las ventajas de las lógicas justificacionistas y de las lógicas falibilistas.

La DC como mecanismo conceptual es útil en cuanto puede contribuir, dada su riqueza metodológica y flexibilidad lógica, a: 1) depurar el SC y ayudar a transformar mejor la naturaleza y la sociedad; 2) conquistar la abundancia del mundo; 3) fortalecer la fraternidad humana. También es útil como mecanismo conceptual, porque dadas sus propiedades epistemológicas mantiene al margen el dogmatismo y del escepticismo, posibilitando depurar las teorías continuamente y así avanzar hacia la construcción de teorías más verosímiles (con mayor grado de verdad), más funcionales, más útiles y, finalmente, exitosas.

La DC como ejercicio racional juzga la verdad o la falsedad de las teorías, aplicando dos tipos de metodologías: (I) las justificacionistas y (II) las falibilistas. Las metodologías de tipo I buscan probar las teorías por medio de experimentos o argumentos, las de tipo II buscan, por medio de experimentos cruciales o argumentos negativos, refutar las teorías. En la tradición filosófica, ambas metodologías han sido excluyentes, en otras palabras, las distintas doctrinas filosóficas han defendido una metodología o rechazado la otra. La DC aquí propuesta, 
plantea superar esta separación, para lo cual se propone que en los análisis de teorías se usen ambos instrumentos metodológicos, según sea la naturaleza de las teorías que se estén examinando.

En el ejercicio de construcción y análisis de teorías a cargo de comunidades científicas, sociedades de conocimiento, tradiciones culturales, sujetos, se ha utilizado con efectividad tanto la metodología tipo I, que representa la tradición filosófica platónica, como la metodología tipo II defendida desde Jenófanes. De facto, una vez que el hombre ha enunciado teorías para explicar la realidad, ha buscado pruebas para justificarlas, verificarlas, confirmarlas y/o testarlas (metodología tipo I $)^{9}$, o ha buscado también criticarlas, refutarlas y/o falsarlas (metodología tipo II). Dada la riqueza tanto de lo dado a la experiencia como a la imaginación humanas, es necesario, si se desea conquistar toda la abundancia, hacer uso de ambas metodologías. La DC intersecta ambas metodologías, abriendo así nuevos caminos para probar la veracidad o falsedad de las teorías. La DC es una defensa al pluralismo metodológico, sin que se tenga que exclamar como el joven Feyerabend: "Adiós a la razón”.

En breve se ilustrará, siguiendo a Tomás de Aquino, el modus operandi de la metodología tipo I, y, siguiendo a Popper, la metodología tipo II.

\section{a) Santo Tomás. Metodología tipo I con propiedades justificacionistas}

Sin hacer justicia a la riqueza del método escolástico, se podría resumir en tres grandes momentos: a) la lectura de un texto, b) las preguntas dirigidas a la indagación de su sentido, y c) la disputa acerca de la verdad de las tesis manifiestas. Esta disputa era enriquecida por comentarios que buscaban mostrar las razones más fuertes que probaran la legitimidad de unas interpretaciones sobre otras. Se nota claramente cómo Tomas de Aquino (Aquino, 1996) en su obra el tratado de la ley y tratado de la justicia, buscaba probar las verdades del cristianismo haciendo uso del método escolástico (p. 4). Sea el ejemplo:

Después de leer (lectio) distintos textos referentes a la ley, tanto teológicos como filosóficos, Tomas de Aquino transita el camino de la disputa. Él pregunta (quiestio) a la tradición ¿Todas las leyes sociales persiguen el bien común? El filósofo dominico pasa a analizar dos afirmaciones excluyentes entre sí, que dan respuesta a ese interrogante. Una respuesta A afirma que las leyes se ordenan a

\footnotetext{
9 "Fue Descartes quien, haciendo de la evidencia el signo de la razón, sólo quiso considerar racionales las demostraciones que, partiendo de ideas claras y distintas, propagaban, con ayuda de pruebas apodícticas, la evidencia de los axiomas a todos los teoremas" (Perelman y Olbrechts, 1989, p- 31).
} 
bienes particulares y una respuesta B afirma que efectivamente la ley se ordena al bien común. Luego de ello, se abre paso a la disputa (disputatio) exponiendo las razones que justifican ambas respuestas.

Tomás expone tres razones que podrían probar A. 1) No siempre el fin último de la ley es el bien común, puesto que los preceptos de la ley también reglamentan bienes particulares. 2) La ley guía a los hombres, éstos hacen acciones particulares, por ende la ley trata de acciones particulares. 3) La razón ordena la ley, y a la razón pertenece tanto el bien común como el bien particular, luego a la ley pertenece tanto el bien común como el particular.

El filósofo continúa el discurso alejándose de la respuesta $\mathrm{A}$, siguiendo esta cadena de racionamientos: Toda ley se debe dirigir a la felicidad común porque la razón fundamenta la ley, de manera que ésta rija y mesure los actos humanos, los cuales deben tender hacia la felicidad. Dado que las partes se ordenan al todo y lo imperfecto se ordena a lo perfecto, así el individuo se debe ordenar a la sociedad, siendo necesario que la felicidad individual se dirija a la felicidad común. Es, pues, necesario que "la ley propiamente se dirija a la felicidad común”. Si el bien no es cosa distinta a la felicidad, se sigue, finalmente, que la ley se ordena al bien común.

Tres razones justifican B y rechazan al tiempo A, a saber: 1) Aunque es cierto que los preceptos se aplican a casos particulares, los de la ley se predican en términos generales; en este sentido, la ley se ordena al bien común. 2) Es razonable que los actos humanos se refieran a situaciones particulares, sin embargo, las acciones se deben dirigir, en cuanto causa final, al bien común. 3) La razón práctica debe ordenarse al fin último, es decir, al bien común. Esta sucesión de razones que sigue Tomás de Aquino (1996), muestra la naturaleza justificacionista que tenía la disputa en este filósofo; de esta forma, con las conclusiones que perseguía, buscaba probar las verdades de la razón o las verdades de la fe.

La conclusión que se sigue de esta muestra es que el método escolástico defendido por Santo Tomás y, especialmente, la disputa, fueron marcadamente de corte justificacionista. Como lo es también la cantidad de prácticas y experimentos científicos en los laboratorios encaminados a probar la verdad de una teoría.

La lógica matemática, por ejemplo, es demostrativa y sigue un patrón justificacionista; los métodos inductivos que se usan en la química y en la biología que pretenden comprobar la veracidad de una teoría también siguen este mismo patrón. Así mismo, las proposiciones que los individuos afirman en el diario vi- 
vir, las cuales se pretenden verificar, confirmar, probar, siguen un canon justificacionista. En fin, el justificacionismo hace parte del racionamiento humano, tanto de la ciencia como del sentido común, como de cualquier otra forma de conocimiento.

Pero también es cierto que hace parte del razonamiento en las ciencias y en el sentido común, la búsqueda incesante de contradecir teorías y proposiciones. Los seres humanos buscamos no sólo probar teorías, sino también falsarlas. Deseamos siempre renovar o sustituir teorías. Así, nuestro razonamiento sigue también un patrón falibilista. Fue Karl Popper quien propuso y desarrolló el falsacionismo, como se expone a continuación:

\section{b) Popper. Metodología tipo II con propiedades falibilistas}

El fin que se persigue en una discusión crítica es acercarse a la verdad; esto no implica que llegue a poseerla, puesto que el conocimiento es de carácter conjetural. La discusión crítica es un mecanismo conceptual que consiste en postular conjeturas audaces y someter las teorías a refutaciones. La naturaleza de este ejercicio crítico es falsacionista, no busca verificar, ni demostrar ni justificar teorías; persigue, por el contrario, examinar las teorías, testarlas, falsarlas. La racionalidad y la honestidad científica consisten en superar la actitud dogmática que lo ancla a la tradición, a través del estímulo de la actitud crítica. Parafraseando a Popper, podríamos decir que un hombre de ciencia honesto debería ser capaz de poner todo en interrogación.

La discusión crítica, entendida como un examen crítico de las teorías, permite desarrollar el conocimiento. Dice Popper: "se habrá observado a través de mi formulación que, cuando hablo del desarrollo del conocimiento científico, lo que tengo en mente no es la acumulación de observaciones, sino el repetido derrocamiento de teorías científicas y su reemplazo por otras mejores o más satisfactorias” (Popper, 1967, p. 264). Así, por ejemplo, la teoría geocéntrica aristotélico-ptolemaica, según la cual la tierra era el centro del universo y entorno a ella giraban los demás planetas, fue reemplazada por la teoría heliocéntrica, la cual explica cómo el centro del universo es el sol y en torno a éste giran, en órbitas circulares, los demás astros.

Esta teoría, defendida por Copérnico y Galileo, refutó el anterior modelo astronómico. No obstante, la teoría siguió teniendo fallas: las órbitas que seguían los planetas no eran círculos perfectos, sino órbitas elípticas; fue Kepler el que se encargó de corregirlas. "La ciencia progresa mediante ideas audaces, mediante 
la exposición de nuevas e insólitas teorías (como la de que la tierra no es plana o de que "el espacio métrico" no es plano) y el abandono de las viejas" (Popper, 1984, p. 209).

Cabe acotar que para Popper cuando la teoría resiste los experimentos cruciales, dado su grado alto de verosimilitud, la teoría resulta corroborada. Lo cual implica que este ejercicio de proponer conjeturas y refutarlas también puede ser exitoso, en la medida en que las teorías que no pueden ser falsadas, gracias a su alto índice de acercamiento a la verdad, resultan siendo aceptadas, parcialmente. "La verdad no es manifiesta, y no es fácil llegar a ella. La búsqueda de la verdad exige, al menos, (a) imaginación, (b) ensayo y error, (c) el descubrimiento gradual de nuestros prejuicios a través (a),(b) y de la discusión crítica" (Popper, 1967, p. 421).

La DC (disputa crítica) resulta de la intersección entre el método escolástico, marcadamente justificacionista y defendido por Tomás de Aquino y el método de discusión crítica, significativamente falibilista promovido por Popper. Esto se ilustra por medio de una analogía.

Existe un isomorfismo entre un juicio y una DC. El objeto del juicio es la aplicación de la justicia. El objeto de la teoría es representar el mundo de la forma más verosímil posible. En un juicio participa un juez, el fiscal, el abogado, el imputado, la ley; en una DC participan los científicos, los refutadores, los justificadores, la teoría y el sistema de representación. Ante el juez se presenta el imputado, el fiscal presenta evidencias que lo condenen, el abogado presenta pruebas para salvarlo, finalmente el juez, con base en la evidencia y en la ley, ejecuta la sentencia. Ante las comunidades científicas se presentan las teorías, los falibilistas (fiscales) presentan test falsador o experimentos cruciales para falsar las teorías; los justificacionistas (abogados) presentan pruebas para verificarlas o confirmarlas; y los científicos (jueces), considerando la fuerza de las razones y los hechos y, basados en la tradición científica de su comunidad, deciden condenar la teoría o salvarla.

En muchos casos, quien ha sido juzgado en un tribunal y condenado, podrá apelar en beneficio de la duda; así también, ante el tribunal de la ciencia, las teorías podrán recobrar vida. De esta manera, como en un juicio se hace uso de las metodologías justificacionistas tipo I y las falibilistas tipo II, nosotros proponemos que en la construcción de conocimiento o, mejor, en la legitimación de la doxa se haga uso de la DC, en la cual se unen ambas metodologías (tipo I y II), con el ánimo de someter las teorías a un juicio más rico y justo. 
Para dinamizar colectivos inteligentes no basta únicamente con filtrar la doxa (opiniones falsas y verdaderas) a través de la disputa crítica (DC). Si bien la doxa legítima (doxa filtrada a partir del mecanismo de DC) es el insumo principal del sentido común, si ésta no es apropiada por los individuos, el círculo virtuoso de los colectivos inteligentes no se desplegaría adecuadamente.

Es necesario entonces, que los diferentes conocimientos depurados, entre ellos la doxa, se transfieran desde los lugares de su producción hacia los colectivos y ello se hace por medio de los sistemas de transferencia. Estos sistemas están compuestos por procesos de democratización, difusión, popularización y apropiación de conocimientos.

\section{Mecanismos de democratización y apropiación del conocimiento y de la doxa legítima}

Para la creación de sociedades inteligentes, no basta con que los índices de generación de Doxa Legítima (DL) sean altos. Esto es, no son suficientes para crear dinámicas sociales inteligentes (que generen desarrollo social); contar con altos índices de producción de conocimiento, de ciencias, tecnologías, de artes y humanidades, si bien es necesario, no es suficiente, ya que se requiere, además de la DL, que ésta esté al alcance de cada individuo que pertenece a un colectivo. La tarea de los sistemas de transferencia radica, precisamente, en crear un flujo virtuoso de a) producción, b) distribución, c) intercambio y d) consumo de conocimiento, a partir de cuatro (4) procesos que se corresponden con los anteriores; éstos son: 1) democratización, 2) difusión y divulgación, 3) apropiación, y 4) popularización de la DL. Los sistemas de transferencia-ST- deben, por tanto, garantizar que la DL se genere y se asimile por el mayor número de agentes dinamizadores de una sociedad, sean éstos: individuos, instituciones o supra instituciones.

\section{a) Democratización}

Pericles de Samos se refería a la polis como “(...) una ciudad libre, un gobierno del pueblo, por el pueblo, para el pueblo, una democracia. La administración se encuentra en manos de la mayoría, no de la minoría” (Rozo, 1993, p. 161). Basta con estas palabras para acercarse al concepto intuitivo de democratización de la doxa legítima. Democratizar la DL implica, mínimo tres condiciones: 1) que la DL sea propiedad colectiva de la sociedad y no de uso privado de quienes la han creado; 2) que cada ciudadano pueda participar en la formulación de políticas públicas para el avance del conocimiento, las artes y las humanidades; 3) 
que los bienes y servicios, resultantes de la DL, sean de dominio público, es decir, que los ciudadanos puedan acceder a los productos del conocimiento, cuando sea menester.

¿Quién debe decidir qué tipos de conocimiento se deben producir? ¿Bajo qué condiciones se debe producir? y ¿para quién producir? En una sociedad ideal, quien debe responder a estas preguntas no son las élites productoras de conocimiento o las empresas, sino toda la sociedad.

¿Quién debe decidir si los estudios de clonación genética deben extenderse a seres humanos? ¿Quién debe decidir cuáles son los alcances y límites experimentales de tales investigaciones? ¿Quiénes deciden qué personas deberán beneficiarse de los futuros avances de la ingeniería genética?

En una sociedad ideal esas respuestas no la tendrían las élites políticas, ni las económicas, ni las científicas; esas respuestas las tendría toda la sociedad; esas decisiones se tomarían por consenso del pueblo. Lo cual no implica que éste tenga la razón, el pueblo se equivoca cientos de veces, empero, al menos, debe tomarse en cuenta el legítimo derecho que tiene para decidir y ser responsable de su futuro. "La relación entre la libertad y la responsabilidad es de doble sentido. Sin la libertad fundamental y la capacidad para hacer una cosa, una persona no puede ser responsable de hacerla" (Sen, 2000, p. 340). Hoy, en las sociedades reales, la creación masiva de plantas de energía nuclear no las decide el pueblo. No obstante -podríamos decir injustamente- mañana, cualquier consecuencia nociva generada por el uso de este tipo de energía, recaerá sobre él, aunque éste (el pueblo) no haya participado ni un ápice en su elección.

\section{b) Difusión y divulgación}

Para aproximarse a un definición intuitiva de los conceptos de difusión y divulgación de la DL, se puede recordar la enciclopedia ${ }^{10}$ organizada por Diderot y D'Alembert. Estos dos intelectuales, representantes dignos del siglo de las luces, lograron recopilar y poner a disposición de información codificada. Hoy las bases de datos virtuales, las bibliotecas, los canales científicos, los museos, la industria cultural, las revistas científicas, los espacios académicos (congresos, foros, simposios), además de otros que tengan parecidos de familia, son ejemplos de avances de la sociedad en materia de divulgación y difusión de la DL.

10 De hecho la enciclopedia hizo pública la tecné. Ver: (Drucker, 1993, p. 38). 
Los procesos de divulgación y difusión repercuten significativamente en el desarrollo social, porque les permite a las personas informarse ${ }^{11} \mathrm{y}$ motivarse acerca de los avances del conocimiento, lo cual puede mejorar las elecciones que tomen los sujetos en relación con las soluciones de sus problemas y, así mismo, redundar en desarrollo humano y desarrollo social. "El futuro de la humanidad dependerá más que nunca de la producción, la difusión y la utilización equitativas del saber" (UNESCO-ICSU, 1999, p. 3). Siguiendo las recomendaciones de J. Ayer, la formación científica y el acceso al lenguaje científico, o lo que significa la difusión científica, debe comenzarse desde edades muy tempranas, para ello debe complementarse la educación formal con la informal; esto con el ánimo de desarrollar una capacidad científica endógena y desarrollar el pensamiento crítico, a partir del cual se pueda asumir con responsabilidad el conocimiento. Es pues, menester para desarrollar sociedades inteligentes, distribuir la DL, lo cual se hace a través de la difusión y divulgación. En la actualidad, por ejemplo, existe un conocimiento aproximado referente a las causas más relevantes del cáncer; las campañas de difusión y divulgación sobre este fenómeno han contribuido a la prevención de este flagelo, pues informan a los sujetos sobre los factores de riesgo y cómo deben subsanarse.

\section{c) Apropiación}

Un acercamiento intuitivo al concepto de apropiación del conocimiento es el que ocurre en los clubes de ciencia para niños en todos los lugares del planeta, en los semilleros de investigación de las universidades o en las comunidades científicas como la Royal Society. En estos espacios se crean unas atmósferas que posibilitan que los sujetos: a) se interesen por el conocimiento, b) desarrollen competencias científicas de orden lógico, metodológico, lingüístico, disciplinario, semántico, ético, entre otros, c) asuman críticamente el conocimiento, y d) lo usen responsablemente.

Por supuesto que la apropiación social del conocimiento sigue esta ruta de formación del espíritu científico o el espíritu del conocimiento, pero es más ambiciosa aun, en cuanto no se limita a motivar, hacer comprender, validar y utilizar la DL en escenarios únicamente de educación, o en comunidades científicas o en departamento de innovación de las empresas, sino que amplía su espectro de dominio a todas las instituciones sociales, comenzando por las familias, pasando por las instituciones y organizaciones, y finalizando en el estado. "Así, la noción

11 "La tarea empieza por el individuo. Tenemos que volvernos usuarios de herramientas". (Drucker, La gerencia en la sociedad futura, 2013, pág. 55). Y la información es una herramienta fundamental en la sociedad actual. 
de apropiación propuesta se mueve en tres niveles: interesarse/comprender, validar y utilizar” (Lozano y Maldonado, 2010, p. 4).

La apropiación social del conocimiento implica que los ciudadanos puedan entender el mundo del conocimiento, asumirlo críticamente y usarlo como mejor convenga al bienestar general; para ello las comunidades científicas, los medios masivos de comunicación, las sociedades del conocimiento, el sector público y privado, el sector social ${ }^{12}$, las industrias culturales, los legisladores, los políticos, los educadores, los educandos ${ }^{13}$, los organizaciones no gubernamentales, los divulgadores de conocimiento y cualquier dinamizador de la sociedad, deberán gestionar acciones, planes, proyectos y programas que puedan garantizar que la sociedad en su conjunto pueda intercambiar efectivamente los avances, bienes y servicios de la ciencia. Ningún proceso de apropiación del conocimiento avanzará sin la interacción efectiva entre individuo y medio social. En este sentido y siguiendo a Popper (1984, p. 379), es necesario afirmar que el individuo habrá de educarse para ser agente social, y la sociedad en su conjunto deberá generar instituciones que garanticen las libertades del individuo.

\section{d) Popularización}

La ciencia se torna popular si, y sólo si el pueblo accede a ella en condiciones de equidad; la sociedad consume bienes y servicios generados gracias al conocimiento. Muchos casos nos acercan a un significado intuitivo del concepto popularización de la DL. Resaltemos aquí, por ejemplo, el hecho tan simple y tan a la mano de cualquier persona por reducir el número de bacterias reinantes en el agua y que resultan nocivas para el cuerpo humano, incrementando la temperatura del agua hasta su nivel de ebullición. En este caso del sentido común, se aplican varios principios de la ciencia, tanto de la biología, en el caso del hábitat de las bacterias, como de la termodinámica, relativo a la temperatura de la materia, así como de la fisiología en lo concerniente al desarrollo del cuerpo humano.

Popularizar la DL es, en consecuencia, poner los avances del conocimiento en las manos de quien lo necesite. "Los bunjin tenían como meta la alfabetización

\footnotetext{
12 No en vano afirma el gurú de la administración: "Sólo el sector social, es decir, las organizaciones no gubernamentales sin ánimo de lucro, puede crear lo que necesitamos hoy: comunidades para los ciudadanos y especialmente para los trabajadores de alto nivel educativo que ya están dominando en las sociedades desarrolladas" (Drucker, 2013, p. 191).
}

$13 \mathrm{El}$ reto y la responsabilidad de los educandos es hoy excepcional. "Tradicionalmente, la escolaridad terminaba cuando comenzaba el trabajo; en la sociedad del conocimiento, nunca termina" (Drucker, 2013, p. 213). 
universal; fueran donde fuesen, persuadían al señor local para que abriera escuelas para los niños de su dominio, accesibles a todos" (Drucker, La sociedad poscapitalista, 1993, p. 195). En este proceso del sistema de transferencia, debe participar el mayor número de agentes posibles. "La popularización de la ciencia y la tecnología supone la acción integrada de generadores de conocimiento, como científicos, investigadores e intelectuales; de difusores de conocimiento, como periodistas, publicistas, museólogos, maestros, productores de audiovisuales de soporte; de miembros de instituciones científicas, culturales y sociales" (OEA, 2005, p. 91). Todos con el propósito firme de dar a cada persona de la sociedad el conocimiento que, de suyo, le pertenece.

Afortunadamente, se ha consolidado un gran acuerdo en torno a la necesidad de popularizar la ciencia (OEA, 2005, p. 16), pues ésta hace posible: a) el desarrollo socioeconómico, ambiental y cultural de los pueblos, b) el asentamiento de una cultura científica, alentando nuevos talentos para la investigación ${ }^{14}, \mathrm{c}$ ) la mejora del talento humano y el avance en la forma creativa de resolución de problemas, d) el desarrollo del pensamiento crítico ${ }^{15}$ de la población en general, lo que permite fortalecer la participación democrática y la contribución al desarrollo sostenible y e) el fortalecimiento del desarrollo individual, pues posibilita la satisfacción personal y la autoestima.

\section{e) Contribución de la doxa legítima al desarrollo social}

Conceptos contemporáneos como calidad de vida, desarrollo humano ${ }^{16}$, desarrollo social, bienestar colectivo, paz, promoción de los derechos, pasan a ser nombres sofisticados de un anhelo común que ya era comentado en los antiguos griegos y que, en la pluma de Aristóteles, tomó forma de aspiración última; esto es, la felicidad. Cada persona desea una vida feliz, una sociedad feliz, en últimas, nuestro propósito es un "mundo feliz". "El fin último de toda industria humana es el logro de la felicidad” (Hume, 1990, p. 197). El problema radica en el contenido empírico de la afirmación. Cualquier persona sana mentalmente acepta que la humanidad desea ser feliz, pero no todas las personas están de acuerdo en qué tipo de carga empírica soporta la definición de felicidad, ni en los medios que se

14 "El éxito y, a decir verdad, la supervivencia misma de cada negocio dependerán cada vez mas de su personal del conocimiento" (Drucker, 2013, pp. 108-109).

15 "Los derechos políticos y humanos, sobre todo los que garantizan la discusión, el debate, la crítica y la disensión abiertos, son fundamentales para los procesos de decisión documentada y reflexionada" (Sen, 2000, p. 191).

16 "El desarrollo consiste en la eliminación de algunos tipos de falta de libertad que dejan a los individuos pocas opciones y escasas oportunidades para ejercer su agencia razonada" (Sen, 2000, p. 16). 
deben seguir para alcanzarla. Lo mismo ocurre con los conceptos contemporáneos ya mencionados (desarrollo social, paz...) cualquiera aspira a ellos, pero discrepamos de su significado.

El buen sentido nos señala que debemos cultivar las ciencias, las humanidades y las artes, para aplicar este conocimiento a la resolución de problemas naturales y culturales y así promover el desarrollo de la sociedad; empero, no logramos ponernos de acuerdo en qué sea eso que llamamos desarrollo social, o ciencias o artes o humanidades. Pese a nuestras dudas y discrepancias, las personas no se hunden en el terreno fangoso porque se atrincheran en las distintas tradiciones y, de hecho, logran avanzar en el lodo ya que se arriesgan y se dan saltos para explorar nuevas rutas impulsadas por teorías audaces.

La DL (doxa legítima) es básicamente ese conjunto de teorías y de saberes relativamente estables, depurados a través de la DC (disputa crítica), los cuales, transferidos a los individuos, hacen que las dinámicas de éstos sean inteligentes. Se aspira a que sujetos inteligentes promuevan el desarrollo social o, si se quiere un término teleológico, se aspira a que sujetos inteligentes puedan alcanzar una vida feliz.

Cuando nos preguntamos ¿cómo contribuye la DL al desarrollo social? Podemos responder varias cosas: Si la DL está constituida por un conjunto de creencias que, aunque sean conjeturas, han sido depuradas después de un proceso de DC; y si se sigue que estas creencias probables y funcionales pasan a ser parte del buen sentido de todos los individuos que conforman un colectivo, a través de la aplicación de los sistemas de trasferencia del conocimiento; entonces, deberá suceder que los individuos utilizarán tal conocimiento para resolver problemas inteligentemente en el orden ecológico, económico, social, cultural, político e ideológico; lo que redundará, por supuesto, en desarrollo social ${ }^{17}$, puesto que la sociedad se compone de estas esferas. Sea el ejemplo: La creación de pan parece ser simple, no obstante, supone un sistema de conocimientos que pasa desde la biología y la química hasta la biotecnología.

Para hacer pan se usa una aplicación tecnológica que consiste en introducir organismos protozoos, denominados levadura, en una mezcla de trigo, agua, sal, mantequilla, entre otros aditamentos. La levadura se alimenta del trigo, éste le

17 El buen sentido enseña que: "El desarrollo exige la eliminación de las principales fuentes de privación de la libertad: la pobreza y la tiranía, la escasez de oportunidades económicas y las privaciones sociales sistemáticas, el abandono en el que pueden encontrarse los servicios públicos y la intolerancia o el exceso de intervención de los estados represivos" (Sen, 2000, pp. 19-20). 
proporciona, a partir de sus proteínas, el hidrógeno, oxígeno, carbono y nitrógeno suficiente para realizar su proceso de reproducción. Como resultado de todo este proceso químico y biológico, se obtiene un voluptuoso pan.

Esta creencia ha sido ensayada (disputa crítica) por distintas culturas desde la egipcia, por lo cual la creencia resulta ser probable y funcional. Este conocimiento ha sido transferido por medio de la práctica en los talleres de procesamiento de pan de generación en generación (sistemas de transferencia). Hoy día, en cientos de lugares del mundo, se hace pan (apropiación del conocimiento), lo cual implica que se han alimentado millones de personas (resolución de un problema social), lo cual contribuye al desarrollo social.

Ahora bien, si un proceso tan simple como éste genera desarrollo social, imagínese qué repercusiones tendría si temas tan importantes como la física cuántica, la nanotecnología, la neurología, entre otros, fueran de domino público; seguramente las condiciones de vida mejorarían. Obviamente que el uso de la ciencia y la tecnología no es siempre provechoso para el género humano, ya la escuela de Frankfurt y, más específicamente, Herbert Marcuse y Erich Fromm, habían realizado una crítica demoledora a los abusos de la tecnología, como lo han hecho cientos de autores desde distintas disciplinas del conocimiento. Sin desconocer esa lamentable realidad, es preferible siguiendo a Hume (1990, p. 251), inclinarse a la defensa del ideal, según el cual la ciencia puede contribuir a mejorar la sociedad tanto como el carácter de quien la cultiva.

Se puede agregar que todo este proceso de legitimación de la doxa y de transferencia de conocimiento a la sociedad, que desemboca en la construcción de sociedades más inteligentes, debe ir acompañado de un proceso ético y axiológico que garantice que la DL se use en función del bien común. El sistema de creencias y hábitos axiológicos que condiciona la decisión de un individuo a actuar conforme al desarrollo social, debe estar regulado necesariamente por dos principios:

A) La consistencia del bien de cada individuo con el bien de la humanidad es, en resumen, el propósito de acción que debe regular la conducta de cada sujeto. Dado que las probabilidades de que un hombre sobreviva aislado de la sociedad son mínimas ${ }^{18}$, el buen sentido impulsa a cada hombre a creer que es mejor vivir

18 "Los individuos viven y actúan en un mundo de instituciones. Nuestras oportunidades y perspectivas dependen sobre todo de las instituciones que existan y cómo funcionan" (Sen, 2000, p. 178. 
en sociedad y a contribuir a que ésta se desarrolle. Actitudes éticas ${ }^{19}$ como el humanismo, el altruismo, la solidaridad, la beneficencia, entre otras de este mismo grupo, pueden contribuir a que, en efecto, una sociedad despliegue su potencial.

B) El concepto de bien de la humanidad está regulado por un concepto de lo que resulta útil. "Podemos observar que en la vida común siempre se apela a la circunstancia de la utilidad; y se supone que no hay mayor elogio que pueda hacerse de un hombre, que el mostrar su utilidad para el público y enumerar los servicios que ha prestado a la humanidad y a la sociedad” (Hume, 1993, pág. 81). El concepto de bien para la humanidad se predica en abstracto, mientras que el concepto de útil ${ }^{20}$ se predica de lo concreto; el conocimiento de lo útil será, pues, relativo a la doxa.

\section{Conclusiones}

Según Tomas Reid, el sentido común es un conjunto de verdades autoevidentes; las cuales son inherentes a la naturaleza humana y son el fundamento de la generación de los conocimientos. Así entendido el sentido común, se caracteriza por ser individual, estático y dogmático. No obstante, el sentido común no es conjunto de verdades evidentes en sí mismas, sino que se modifican a la par que cambia el conocimiento y la historia humana.

El sentido común es en consecuencia un conjunto se creencias que resultan ser útiles para la vida, pero que se pueden transformar. De aquí se sigue que el sentido común es colectivo, dinámico y flexible. Este es la base de todo conocimiento y cumple una función de promoción del desarrollo social, pues es al fin y al cabo el primer conjunto de saberes con que cuenta cualquier individuo para supervivir y adaptarse a la cultura.

El sentido común está conformado por un núcleo de creencias tanto falsas como verdaderas que deben ser depuradas por medio de una disputa crítica, de modo que puedan servir de fundamento o de materia prima para construir nuevos saberes. "Lo que habitualmente se llama sentido común consiste en una serie

19 Hume ya había señalado que para la humanidad entera resultaba siempre agradable y útil el cultivo de la inclinaciones sinceras y generosas hacia nuestros congéneres; incluso resaltó algunas como cabalmente importantes, entre ellas: "...la beneficencia y el humanitarismo, la amistad y la gratitud, el afecto natural y el espíritu cívico" (Hume, 1993, p. 41).

20 En términos útiles esta sería la exigencia ética básica: "Disminuir el dolor" de nuestros semejantes (Popper, 1984, 466). 
de creencias admitidas en el seno de una sociedad determinada, cuyos miembros suponen que cualquier ser razonable las comparte" (Perelman y Olbrechts, 1989, pp. 768-769).

Una forma de salvaguardar los saberes del sentido común, los saberes ancestrales y los conocimientos no científicos de los diferentes colectivos, es a través de la implementación de metodologías flexibles y racionales que permitan conservar y democratizar la sapiencia adquirida por los individuos desde sus tradiciones. Esta metodología se denomina disputa crítica.

La disputa crítica es un mecanismo metodológico que intersecta las lógicas justificacionistas, cuyo fin es verificar teorías, y las lógicas falibilistas, cuya modus operandi es refutar teorías. Este mecanismo -dado su grado de flexibilidad y racionalidad- posibilita avanzar en la depuración y generación de creencias. "Gracias a la posibilidad de una argumentación que proporciona razones, pero razones no apremiantes, es posible escapar del dilema: adhesión a una verdad objetiva y universalmente válida o recurso a la sugerencia y a la violencia para que se admitan sus opiniones y decisiones" (Perelman y Olbrechts, 1989, p. 773).

Las creencias verosímiles depuradas a través de la disputa crítica pueden generar inteligencia colectiva, una vez que los distintos colectivos humanos se apropian de ellas por medio de los mecanismos de democratización de saberes. Estos mecanismos, si desean impactar positivamente el desarrollo social, deben proteger y estimular el pensamiento crítico y el libre debate de las ideas. "La razón, al igual que la ciencia, se desarrolla a través de la crítica mutua; la única forma posible de "planificar" su desarrollo es fomentar aquellas instituciones que salvaguardan la libertad de dicha crítica, es decir, la libertad de pensamiento" (Popper, 1984, p. 394).

Los saberes transferidos a los individuos crean un círculo virtuoso de apropiación del patrimonio cultural y cognitivo, ello impacta positivamente la sociedad pues las personas usan los distintos conocimientos en función de la discusión ${ }^{21}$ y consecuente solución de problemas económicos, sociales, políticos, sociales y ambientales.

El sentido común, entendido como un conjunto de creencias primitivas compartidas por la mayoría de personas en una sociedad, tiene su origen en una tra-

21 El acceso a la educación universal contribuye ostensiblemente al robustecimiento del sentido común de los individuos y mejora su función agentica en la sociedad. "La expansión de la educación básica también puede mejorar la calidad de los debates públicos” (Sen, 2000, p. 354). 
dición. Como memoria e inteligencia colectiva de un pueblo, el sentido común es alimentado por las creencias y opiniones de los individuos, de las sociedades del conocimiento y de la cultura, gestadas a lo largo de la vida de los pueblos, transmitidas a partir de la educación o aprendidas por medio de la imitación. Estos primeros principios representan el punto de partida del conocimiento humano y de la adaptación a la cultura de cualquier individuo. El saco de creencias que conforman el SC, posee tanto creencias falsas como verdaderas.

Aunque el hombre esté imposibilitado para hallar verdades (entendidas éstas como certeza $\left.{ }^{22}\right)$, por lo menos puede alcanzar a identificar creencias verosímiles, esto es, enunciados acerca del mundo que si bien no logran describirlo tal como es, al menos sí alcanzan a hacer una descripción acerca de él, aproximada. "En lugar de fundamentar nuestras teorías filosóficas en verdades definitivas e indiscutibles, tomaremos como punto de partida el hecho de que los hombres y los grupos humanos se adhieren a toda clase de opiniones con una intensidad variable, que sólo se puede conocer al ponerla a prueba” (Perelman y Olbrechts, 1989, pp. 768-69).

Para separar las creencias falsas de las verosímiles del SC, se deben someter todas las creencias a una disputa crítica (resumiendo DC) permanente; lo que implica hacer un doble ejercicio de revisión de creencias y justificación. Una vez que se logran separar las teorías falsas de las verosímiles, se da paso a la construcción del buen sentido. El buen sentido lo constituyen el conjunto de creencias, conocimientos y opiniones verosímiles, los cuales resultan ser efectivos, una vez aplicados a la resolución de problemas. El buen sentido se puede denominar doxa legítima (resumido como DL), pues está conformado por opiniones y conocimientos científicos, tecnológicos, técnicos, filosóficos, religiosos, humanísticos, artísticos, entre otros, que fueron depurados, en su paso, por la disputa crítica.

La DL, entendida como el conjunto de creencias verosímiles ${ }^{23}$, nutre las acciones de los individuos, de las instituciones y de las colectividades, cumpliendo así la función de desarrollar la sociedad. Cuando un individuo, una institución o un colectivo enfrentan un problema y usan, para darle solución a la dificultad, conocimiento conjetural verosímil, esto es, DL, es altamente probable que el resultado sea satisfactorio. En este orden de ideas, la DL cumple la función

22 Bien hace en afirmar (con relación al conocimiento absolutamente cierto) Perelman \& Olbrechts (1989, p. 74): "Las concepciones que los hombres se han dado a lo largo de la historia, "hechos objetivos" o "verdades evidentes", han variado lo suficiente para que desconfiemos al respecto".

23 "El análisis de la veracidad o aceptabilidad de las afirmaciones depende del contexto de las afirmaciones en hechos relevantes, valores, creencias y situaciones" (Reeder, 1995, 12). 
de ser un factor contribuyente al desarrollo social, puesto que permite que las dinámicas de individuos, instituciones y colectivos, sean inteligentes y, por ello, generen progreso.

Lo que garantiza que las dinámicas de una sociedad sean inteligentes, es que la DL sea asimilada por medio de un sistema de transferencias (ST) por cada individuo, institución o colectivo que conforma la sociedad. Este sistema de transferencia se divide en cuatro (4) procesos operativos, a saber: 1) democratización, 2) difusión y divulgación, 3) apropiación, 4) popularización. Una vez que la sociedad asimila de suyo la DL, se crean dinámicas sociales inteligentes (DiSI); éstas son las acciones y praxis de los individuos, instituciones y colectivos, que se ejecutan para resolver todo tipo de problemas y generar así desarrollo social (DS). Del resultado de todo este proceso emerge un sentido común enriquecido (SC2), dando origen de nuevo al ciclo, donde esta nueva fuente de conocimiento debe ser sometida a una disputa crítica (DC). La DC necesita un ambiente propicio para su despliegue, necesita una sociedad abierta (SA).

Finalizando, el proceso anterior se puede resumir en el siguiente esquema: $\{\{\mathrm{SC}:[\mathrm{DC}]: \rightarrow \mathrm{DL}(\mathrm{ST}) \rightarrow \mathrm{DiSI}=\mathrm{DS}\} \rightarrow \mathrm{SC} 2\} \mathrm{SA}$

El sentido común (SC) es filtrado (:: $[$ ]:) por la disputa crítica (DC), lo cual genera $(\rightarrow)$ doxa legítima (DL); ésta es transmitida a los individuos, instituciones y colectividades por medio de un sistema de transferencia (ST); dicho resultado genera dinámicas sociales inteligentes (DiSI), lo cual equivale $(=)$ a desarrollo social (DS). Todo el precedente proceso genera nuevamente sentido común (SC2) y así comienza otro ciclo más. El funcionamiento de este esquema sólo es posible en una sociedad abierta ${ }^{24}(\mathrm{SA})$, donde los individuos puedan $\operatorname{razonar}^{25} \mathrm{y}$, libremente, disputar y actuar.

\section{Referencias}

Aquino, T. (1996).Tratado de la ley. México: Porrúa.

Drucker, P. F. (1993). La sociedad poscapitalista. Madrid, España: Apóstrofe.

\footnotetext{
24 "El éxito de una sociedad ha de evaluarse, desde este punto de vista, principalmente en función de las libertades fundamentales de que disfrutan sus miembros" (Sen, 2000, p. 35).

25 "La idea de utilizar la razón para identificar y promover las sociedades mejores y más aceptables ha sido una poderosa fuerza impulsora de los pueblos en el pasado y continúa siéndolo hoy" (Sen, 2000, p. 300).
} 
Drucker, P. F. (2013). La gerencia en la sociedad futura. Bogotá, Colombia: Norma.

Hessen, J. (1994). Teoría del conocimiento. Bogotá, Colombia: Panamericana

Hume, D. (1993). Investigación sobre los principios de la moral. Madrid, España: Alianza.

Hume, David. (1987). Ensayos políticos. España: Tecnos.

Kant, I. (2012). Contestación a la pregunta: ¿Qué es la ilustración? México: Taurus.

Perelman, C., y Olbrechts, L. (1989). Tratado de la argumentación. Madrid, España: Gredos.

Popper, K. R. (1967). Conjeturas y refutaciones. Barcelona, España: Paidós.

Popper, K.R. (1974). Conocimiento objetivo. Madrid, España: Tecnos.

Popper, K.R. (1994). En búsqueda de un mundo mejor. Barcelona, España: Paidós.

Popper, K. R. (1984). La sociedad abierta y sus enemigos. Barcelona, España: Orbis, S.A.

Reeder, H. P. (1995). Argumentando con cuidado. Bogotá, Colombia: Universidad Pedagógica Nacional y San Pablo.

Reid, T. (2004). Investigaciones sobre la mente humana, según los principios del sentido común. Madrid, España: Trota.

Sen, A. (2000). Desarrollo y libertad. Colombia: Planeta.

Stroud, B. (1991). El escepticismo filosófico y su significación. México: Fondo de Cultura Económica

Organización de las Naciones Unidas para la Educación, la Ciencia y la Cultura,UNESCO-ICSU. (1999). Declaración de Budapest: Declaración sobre la ciencia y el uso del saber científico. Hungría: UNESCO. 